AJHSE Vol: 2 (2): 63-70, 2021

DOI: 10.52417/ajhse.v2i2.160

Accepted Date: Sept. 30, 2021

(C) 2021. CC License 4.0

www.ajhse.org

\title{
ANTIBIOTICS IN THE HANDS OF COMMUNITY PHARMACISTS: A PROSPECTIVE AVENUE FOR COMMUNITY BASED ANTIMICROBIAL STEWARDSHIP INITIATIVE
}

\author{
${ }^{* 1}$ Isabel, N. A., ${ }^{2}$ Joshua, O. I. \& ${ }^{3}$ Efe, A. E. \\ 1,2,3 Department of Clinical Pharmacy \& Pharmacy Practice, Faculty of Pharmacy, University of Benin, Benin City, Nigeria \\ *Corresponding Author's E-mail: isabel.aika@ uniben.edu Phone: +2348082826539
}

\begin{abstract}
$\mathrm{A}$ ntimicrobial stewardship (AMS) is high on the agenda of global health organizations with an increasing interest in community-based AMS initiatives, as this is where the majority of antibiotic use occurs. This study sought to evaluate the practice of community pharmacists toward antibiotic use and the likely need for AMS. This was a descriptive cross-sectional study conducted among registered community pharmacists in Benin City, Nigeria. A structured questionnaire was used for data collection. All study participants were duly informed on study objectives and informed consent was sought. The data obtained from the study were analyzed using IBM SPSS version 22. Of the 101 pharmacists who participated in the study, $92(91.1 \%)$ dispensed antibiotics without prescription. The most prescribed antibiotic is Ciprofloxacin 59(58.42\%), followed by Amoxicillin 42 (41.58\%) and Amoxicillin-Clavulanic acid 41 (40.59\%). Ninety-six (95\%) of the pharmacists use antibiotics agents as an adjunct in Typhoid fever treatment, and 78(77.2\%) of them use it as an adjunct in Malaria treatment. Cost $32(31.68 \%)$ is the most common reason for dispensing antibiotics without laboratory investigation and physician's consultation. Most (93.1\%) pharmacists agree that they need training on antimicrobial stewardship practice. The antibiotic prescription pattern among community pharmacists was high, the possibility of antibiotic misuse in the hands of community pharmacists without appropriate guidelines cannot be overlooked. This emphasizes the need for the inclusion of community pharmacies in antimicrobial stewardship programs.
\end{abstract}

Keywords: Antibiotics, Pharmacists, community pharmacy, Antimicrobial Stewardship, Prescribing

LICENSE: This article by African Journal of Health, Safety and Environment (AJHSE) is licensed and published under the Creative Commons Attribution License 4.0 International License, which permits unrestricted use, distribution, and reproduction in any medium, provided this article is duly cited.

COPYRIGHT: The Author(s) completely retain the copyright of this published article.

OPEN ACCESS: The Author(s) approves that this article remains permanently online in the open access (OA) model

QA: This Article is published in line with "COPE (Committee on Publication Ethics) and PIE (Publication Integrity \& Ethics)". 


\section{INTRODUCTION}

Misuse of antibiotics either by healthcare providers through unnecessary prescribing and dispensing or by selfmedicating patients is considered a major cause of antimicrobial resistance with serious worldwide health and economic consequences (CDC 2013). Furthermore, the misuse of antibiotics is associated with increased incidence of adverse reactions of antibiotics in the population. Antimicrobial resistance has also become a portent of a postantibiotic era where minor infections that were curable for decades could become fatal. There is evidence that antibiotic resistance is linked to antibiotic exposure in a population as well as within an individual. A systematic review reveals that patients prescribed antibiotic inappropriately for respiratory or urinary tract infection can develop bacterial resistance to that antibiotic that may last for up to 12 months after the antibiotic was prescribed. The more often the patient has a course of antibiotics the more opportunity that patient's bacteria have to develop multiple or ongoing resistance (Costelloe et al., 2010). Community pharmacies in several low- and middle-income countries are considered the first point of contact for patients to seek medical and wellness advice. In such countries, the majority of the population seeks immediate health advice from community pharmacists rather than physicians for many reasons including accessibility, lower cost and less time-consuming services (Bahnassi et al., 2015; Larissa et al., 2008). While some pharmacists are already involved in outpatient antimicrobial stewardship activities and are having an impact on reducing inappropriate prescribing by physicians in developed countries like Canada, there is an emerging opportunity for community pharmacists to help address antimicrobial resistance in the context of pharmacist prescribing (Julie $e t$ al., 2021; Bishop et al., 2019).

In Nigeria, antibiotics is within reach of the population, and study shows that many people get their medications from community pharmacies compared to from hospitals where qualified doctors examine and prescribe for patients (Wertheim et al., 2017). Against this backdrop of patients self-medicating with antibiotics inappropriately, community pharmacists also freely prescribe or dispense medications including antibiotics to patients. This study seeks to investigate community pharmacist's perception on antibiotic/antimicrobial prescribing or dispensing, use and antimicrobial stewardship.

\section{METHODOLOGY}

Study design/setting: The study was a descriptive cross-sectional study among community pharmacists between May and December, 2018. The study was carried out among pharmacists in community pharmacies in Benin City, Edo State, Nigeria. The areas mainly used for the study were; Oredo, Egor, Ikpoba Okha and Ovia North East Local Government Areas.

\section{STUDY POPULATION}

The inclusion criteria for participation in the study were registered pharmacists working in community pharmacies or have been managing a community pharmacy for at least six months prior to the study and expressed willingness to participate in the study. Exclusion criteria were pharmacy interns, pharmacy support staff, and those unwilling to participate in the study. 


\section{DATA COLLECTION}

A structured interviewer questionnaire was used for data collection. The questionnaire has three sections; The section A was used to collect information on pharmacist's demographics, while the section B and section C were used to obtain information about antimicrobial resistance, reasons for prescribing/dispensing antimicrobials, the role of community pharmacists in the use of antimicrobials, commonly encountered microbial infections and routinely dispensed antimicrobial drugs. Section B of the questionnaire was graded in a five-point Likert scale from 1 representing strongly disagree to five representing strongly agree. The questionnaire also comprised of a section for three open ended questions namely; The top three most encountered infections in community practice, the top three most dispensed antimicrobial and the main reason for dispensing antimicrobials without a prescription by pharmacists in community practice.

\section{ETHICAL CONSIDERATION}

Ethical clearance was obtained from the ethical and review committee of Faculty of Pharmacy, University of Benin. All participants of the study were orally informed about the objectives and anonymity of the study and verbal informed consents were sought from participants before questionnaires were administered. All data collected were kept confidential.

\section{DATA ANALYSIS}

The data obtained from the survey were entered into Microsoft excel and transferred to IBM Statistical Package for Social Sciences (SPSS) version 22. Descriptive statistics are presented as frequency tables.

\section{RESULTS}

A total of 101 respondents participated in the study of which 65(64.4\%) were between 25-34 years of age, while about $3(3 \%)$ were 65 years old and above. There was about equal proportion of male $(52 \%)$ and female $(47 \%)$ in the study. About 90(89.1\%) of the respondent have Bachelor of Pharmacy (B Pharm). Majority (71.3\%) of the respondents were employed in a community pharmacy. More than half of the respondent 53(52.5\%) have practiced for 1-5 years and 10(9.9\%) have been in practice for over 25years. Table 1 shows other details.

Table 2 details practice of antimicrobial/antibiotic use among respondents. More than $70 \%$ of them indicate to patients which medication is an antibiotic and tell patients to complete their dose with varying degree, still, almost all study participants $92(91.1 \%)$ dispense antibiotics without a prescription and when they do it is also without a laboratory investigation.

Table 4 shows commonly dispensed antimicrobials in community pharmacies. Ciprofloxacin $(58.42 \%)$, followed by Amoxicillin (41.58\%), and Amoxicillin-Clavulanic acid (40.59\%) were mostly prescribed or sold to patients, while Levofloxacin (4.95\%) is the least used. 
Table 1: Demographics of Participants $\quad \mathrm{N}=101$

\begin{tabular}{ll}
\hline Item & \multicolumn{1}{c}{$\begin{array}{c}\text { Frequency (Percentage) } \\
\text { F } \mathbf{\%})\end{array}$} \\
\hline Age & \\
$25-34$ & $65(64.4)$ \\
$35-44$ & $21(20.8)$ \\
$45-54$ & $8(7.9)$ \\
55 & $4(4.0)$ \\
64 & $3(3.0)$ \\
$\geq 65$ & \\
Sex & \\
Male & $53(52.4)$ \\
Female & $48(47.6)$ \\
Education & \\
BPharm & $50(49.5)$ \\
PharmD & $40(39.6)$ \\
Postgraduate degree & $11(10.9)$ \\
Community pharmacy & \\
Employed & $72(71.3)$ \\
Owner & $29(28.7)$ \\
Years of Practice & \\
$1-5$ & $53(52.5)$ \\
6-10 & $26(25.7)$ \\
$11-16$ & $8(7.9)$ \\
$\geq 16$ & $14(13.9)$ \\
\hline
\end{tabular}

\section{DISCUSSION}

The main role of community pharmacies and pharmacists is dispensing medications to patients both prescription and non-prescription (over the counter) thus making medications accessible to patients in their communities. This traditional role has now expanded to include various services from offering counseling, immunization, screening, conducting some tests, and more recently pharmaceutical care services, some countries in developed countries allow qualified pharmacists to prescribe some medications. Dispensing of antibiotics without prescription in community pharmacies is an illegal practice in most developing countries like Nigeria (Larissa et al., 2008). The rate at which pharmacists engaged in this practice is very high at $91.1 \%$ from this study. In a study done in another part of Nigeria, and claims in experience for empirical treatment make them dispense antibiotics to patients. These assumptions are insidious as evidence suggests that antibiotics can be inappropriately used to treat a wrong infection thus exposing patients to resistance and treatment failure (Costelloe et al., 2010), more so, it can be deduced from these assumptions that community pharmacists see dispensing antibiotics as a means to drive sales, as patients will favour paying less to get medications conveniently compared to paying more for medical consultation and laboratory test, besides the authors reported that of the 98 community pharmacists surveyed, about two-third (64.3\%) of them were aware that dispensing antibiotics without prescription is illegal. However, this malpractice was common as $39.7 \%$ of the respondents indicated that they dispensed antibiotics without prescription five times or more in a day (Usman et al., 2020). 
Table 2: Practice of Antimicrobial use among Respondents ( $\mathrm{N}=101)$

\begin{tabular}{|c|c|c|c|c|c|}
\hline Variables & $\begin{array}{l}\text { Never } \\
\text { N }(\%)\end{array}$ & $\begin{array}{l}\text { Severally } \\
\mathrm{N}(\%)\end{array}$ & $\begin{array}{l}\text { Fairly Often } \\
\mathbf{N}(\%)\end{array}$ & $\begin{array}{l}\text { Usually } \\
\mathbf{N}(\%)\end{array}$ & $\begin{array}{l}\text { Always } \\
\mathbf{N}(\%)\end{array}$ \\
\hline $\begin{array}{l}\text { I will need continuing education in } \\
\text { antimicrobial stewardship. }\end{array}$ & $7(6.9)$ & $4(4.0)$ & $10(9.9)$ & $27(26.7)$ & $53(52.5)$ \\
\hline $\begin{array}{l}\text { I use antimicrobial agents as an adjunct in } \\
\text { suspected malaria treatment }\end{array}$ & $23(22.8)$ & $9(8.9)$ & $33(32.7)$ & $27(26.7)$ & $9(8.9)$ \\
\hline $\begin{array}{l}\text { I use antimicrobial agents as an adjunct in } \\
\text { suspected typhoid fever treatment }\end{array}$ & $5(5.0)$ & $7(6.9)$ & $14(13.9)$ & $39(38.6)$ & $35(34.7)$ \\
\hline $\begin{array}{l}\text { I clearly indicate to patients which of their } \\
\text { medication is an antimicrobial drug }\end{array}$ & $2(2.0)$ & $2(2.0)$ & $3(3.0)$ & $23(22.8)$ & $71(70.3)$ \\
\hline $\begin{array}{l}\text { I tell patients to complete their } \\
\text { antimicrobial dose }\end{array}$ & $1(1.0)$ & 0 & $3(3.0)$ & $15(14.9)$ & $82(81.2)$ \\
\hline $\begin{array}{l}\text { I ask patient's history and symptoms of } \\
\text { their infections before deciding to dispense } \\
\text { antimicrobials. }\end{array}$ & $3(3.0)$ & $1(1.0)$ & $1(1.0)$ & $17(16.8)$ & $78(77.2)$ \\
\hline $\begin{array}{l}\text { I sought additional clinical information } \\
\text { (e.g. ADRS, allergy, drug interactions) } \\
\text { before deciding to dispense the } \\
\text { antimicrobial agent }\end{array}$ & $2(2.0)$ & $4(4.0)$ & $10(9.9)$ & $34(33.7)$ & $51(50.5)$ \\
\hline $\begin{array}{l}\text { I dispense antimicrobial agents without } \\
\text { complete laboratory information (e.g. } \\
\text { Culture sensitivity test Widal test, swab test } \\
\text { etc.) }\end{array}$ & $9(8.9)$ & $15(14.9)$ & $48(47.5)$ & $26(25.7)$ & $3(3.0)$ \\
\hline $\begin{array}{l}\text { I dispense antimicrobials without a } \\
\text { prescription }\end{array}$ & $9(8.9)$ & $11(10.9)$ & $43(42.6)$ & $26(25.7)$ & $12(11.9)$ \\
\hline
\end{tabular}

More than half of the infections commonly encountered and treated with antibiotics in community pharmacies is typhoid fever (50.50\%) followed by upper respiratory infection (32\%) and urinary tract infection (22.77\%) as shown in Table 3.

Table 3: Infections Commonly Treated with Antibiotics in Community Pharmacies

\begin{tabular}{ll}
\hline Infections & \multicolumn{1}{c}{ Frequency/Percentage } \\
& $\mathbf{N}(\boldsymbol{\%})$ \\
\hline Staphylocococcus aureus & $19(18.81)$ \\
Skin and soft tissue infection & $15(14.85)$ \\
Urinary tract infection & $23(22.77)$ \\
Sexually transmitted infection & $20(19.8)$ \\
Upper respiratory tract infection & $33(32.67)$ \\
Malaria & $21(20.79)$ \\
Typhoid fever & $51(50.50)$ \\
Candidiasis & $22(21.78)$ \\
\hline
\end{tabular}


Table 4: Commonly Dispensed antimicrobial/antibiotics in Community Pharmacies

\begin{tabular}{ll}
\hline Antibiotics & Frequency/Percentage N(\%) \\
\hline Levofloxacin & \\
Metronidazole & $5(4.95)$ \\
Amoxicillin-Clavulanic acid & $10(9.90)$ \\
Amoxicillin & $41(40.59)$ \\
Ciprofloxacin & $42(41.580$ \\
Ampiclox & $59(58.42)$ \\
\hline
\end{tabular}

Cost $(31.68 \%)$ and empirical treatment (31.68\%) were the most common reasons for dispensing antimicrobials without prescription (Table 5).

Table 5: Reasons for Dispensing Antibiotics without Prescription

\begin{tabular}{ll}
\hline Reasons & Frequency/Percentage N (\%) \\
\hline Cost & $32(31.68)$ \\
Treatment based on prior knowledge & $8(7.92)$ \\
Patient's impatience/request & $17(16.83)$ \\
Empirical treatment & $32(31.68)$ \\
\hline
\end{tabular}

Other countries in low-middle-income regions have reported high participation in this practice, $66.1 \%$ in Egypt, Syria (87\%), Ethiopia (93.5\%), and 94\% in India (Abdullah et al 2019; Al-Faham et al., 2011; Erku et al., 2016; Salunkhe et al., 2013). Several factors contribute to this menace in practice among community pharmacists. Participants in our study reported that the cost of patient's consulting qualified physicians, laboratory investigation indirect cost accrued from such visits. Another factor that encourages this practice is dispensing regulations and their enforcement across countries. Nigeria has a weak regulatory mechanism which foils antibiotic misuse, unlike in Zimbabwe with strict regulation where pharmacists dissuade from dispensing antibiotics without prescription for fear of losing their license to practice, this explains the reason behind the low dispensing rates of antibiotics observed in that African country (Nyazema et al., 2007). Similarly, in Chile, there was a significant reduction of antibiotic illegal dispensing after enforcement of regulatory measures, this led to reduction in antibiotic consumption (Bavestrello $e t$ al., 2002). Until Nigerian health authorities take actions to tighten regulation of prescribing and dispensing laws together with regulation of drug distribution, illegal antibiotic dispensing will remain an acceptable practice with the attendant negative consequences mounting up.

Typhoid fever and malaria infections are the top infections pharmacists use antibiotics for in this study. These infections are the most prevalent in the Country; this is in tandem with the most frequently dispensed antibiotics which are Ciprofloxacin, Amoxicillin and Amoxicillin-Clavulanic acid. Ciprofloxacin is in the Watch category of World Health Organization antibiotic list, considering the fact that malaria and typhoid are recurrent infections thus exposing patients again and again to these antibiotics. Usman et al., (2020) in their study reported that antibiotics dispensed 
without prescription were used for the treatment of urinary tract infections (83.7\%), typhoid fever (83.7\%) and sexually transmitted infections (66.3\%), further showing that typhoid fever is an infection common in the country for which antibiotic is used.

Some community pharmacy services in the Southern region of the country recently included pharmaceutical care delivery likely due to the fact that some pharmacists have obtained PharmD degree. Further education and training of healthcare professionals including pharmacists cannot be overemphasized especially in the aspect of antimicrobial stewardship. Almost all the pharmacists in this study have need for training on antimicrobial stewardship practice. Pharmacists are important members of the healthcare team and they play a major role in medicine use and the provision of advice regarding appropriate medicines use. Education and training of pharmacists has the potential to influence the behaviour of healthcare team members and consumers as part of a multidimensional strategy for changing practice and ensure the quality use of antibiotics. They are well placed to improve the understanding of antibiotics and inform their judicious use by direct contact with consumers in the community and in hospitals (Sakeena et al., 2018). Comprehensive and relevant education and training on the use of antibiotics and AMR is essential for pharmacists in order that they may take a leading role in changing behaviours regarding antibiotic consumption in all healthcare settings.

\section{CONFLICT OF INTEREST}

All authors declare no conflict of interest

\section{REFERENCES}

Abdullah I. Abdelaziz, Abdelrahman G. Tawfik, Khaled A. Rabie, Mohamad Omran, Mustafa Hussein, Adel AbouAli, \& Al-Shaimaa F. Ahmed (2019) Q Quality of Community Pharmacy Practice in Antibiotic Self-Medication Encounters: A Simulated Patient Study in Upper Egypt. Antibiotics (Basel). Jun; 8(2): 35.

Al-Faham Z., Habboub G., Takriti F (2011). The sale of antibiotics without prescription in pharmacies in Damascus, Syria. Journal Infection Developing Countries.;5:396-399. doi: 10.3855/jidc.1248.

Bahnassi A. A qualitative analysis of pharmacists' attitudes and practices regarding the sale of antibiotics without prescription in Syria. Journal of Taibah University Medical Science. 2015; 10:227-233. doi: 10.1016/j.jtumed.2014.09.001.

Bavestrello L., Cabello A., Casanova D (2002). Impact of regulatory measures in the trends of community consumption of antibiotics in Chile. Revista Medica De Chile; 130:1265-1272.

Bishop, C, Yacoob, Z, Knobloch, MJ, Safdar, N (2019). Community pharmacy interventions to improve antibiotic stewardship and implications for pharmacy education: a narrative overview. Research Social Admistrative Pharmacy 15(6):627-31.

Control and Prevention, US Department of Health and Human Services (2013). Antibiotic Resistance Threats in the United States. Centres for Disease Control and Prevention, US Department of Health and Human Services; Atlanta, GA, USA: 2013.

Costelloe C, Metcalfe C, Lovering A, Mant D, Hay A (2010). Effect of antibiotic prescribing in primary care on antimicrobial resistance in individual patients: systematic review and meta-analysis. British Medical Journal 340:c2096 
Erku D.A., Mekuria A.B., Surur A.S., Gebresillassie B.M (2016). Extent of dispensing prescription-only medications without a prescription in community drug retail outlets in Addis Ababa, Ethiopia: A simulated-patient study. Drug Healthcare Patient Safety.;8:65. doi: 10.2147/DHPS.S106948.

Julie Hui-Chih Wu, Fatima Khalid, Bradley J (2021). Langford. Community pharmacist prescribing of antimicrobials: A systematic review from an antimicrobial stewardship perspective. Canadian pharmacists Journal, Review Article https://doi.org/10.1177/1715163521999417

Khan, M. U., Hassali, M. A. A., Ahmad, A., Elkalmi, R. M., Zaidi, S. T. R., \& Dhingra, S. (2016). Perceptions and practices of community pharmacists towards antimicrobial stewardship in the state of Selangor, Malaysia. PloS one, 11(2), e0149623.

Larissa Grigoryan, Johannes G. M. Burgerhof, John E. Degener, Reginald Deschepper, Cecilia Stålsby Lundborg, Dominique L. Monnet, Elizabeth A. Scicluna, Joan Birkin, Flora M. Haaijer-Ruskamp (2008)_. Determinants of self-medication with antibiotics in Europe: the impact of beliefs, country wealth and the healthcare system. Journal of Antimicrobial Chemotherapy, Volume 61, Issue 5, Pages 1172-1179

Nyazema N., Viberg N., Khoza S., Vyas S., Kumaranayake L., Tomson G., Lundborg C.S (2007). Low sale of antibiotics without prescription: A cross-sectional study in Zimbabwean private pharmacies. Journal of Antimicrobial Chemotherapy. ; 59:718-726. doi: 10.1093/jac/dkm013

Wertheim HFL, Chuc NTK, Punpuing S, et al., (2017). Community-level antibiotic access and use (ABACUS) in low- and middle-income countries: finding targets for social interventions to improve appropriate antimicrobial use-an observational multi-centre study. Wellcome Open Research; 2: 5

Sakeena M. H. F, Alexandra A. Bennett, Andrew J. McLachlan (2018). Enhancing pharmacists' role in developing countries to overcome the challenge of antimicrobial resistance: a narrative review. Antimicrobial Resistance \& Infection Control volume 7, Article number: 63

Salunkhe S., Pandit V., Dawane J., Sarda K., More C (2013). Study of over-the-counter sale of antimicrobials in pharmacy outlets in Pune, India: A cross sectional study. International Journal Pharmacy Bio Sci. 4:616622 .

Usman Abubakar and Balamurugan Tangiisuran (2020). Knowledge and practices of community pharmacists towards non-prescription dispensing of antibiotics in Northern Nigeria International Journal of Clinical Pharmacy volume 42, pages 756 